\section{Wish upon a Starlite}

\author{
By Omar Fabián
}

$\mathrm{O}$ August 22, 1985, the crew and passengers aboard the River Orrin, a British Airtours plane en route to the island of Corfu in Greece, heard a loud thump. Believing a ruptured tire to be the culprit, the pilots slowed their takeoff and began steering the plane off the runway to assess the situation. Within seconds, the fuselage was ablaze. The loud thump, it turned out, was not the sound of a blown-out tire- - but that of a blown-out engine. The fire that engulfed the cabin claimed 55 lives.

The incident was pivotal to overhauling aviation safety measures, as delays in opening the cabin doors caused most to perish from smoke inhalation. For a plastics enthusiast from Hartlepool, England, it was a personal challenge. There simply had to be a better cabin material that didn't burn as easily.

Maurice Ward was no scientist but rather an avid tinkerer. As a hairdresser in the 1960s, Ward would mix his own

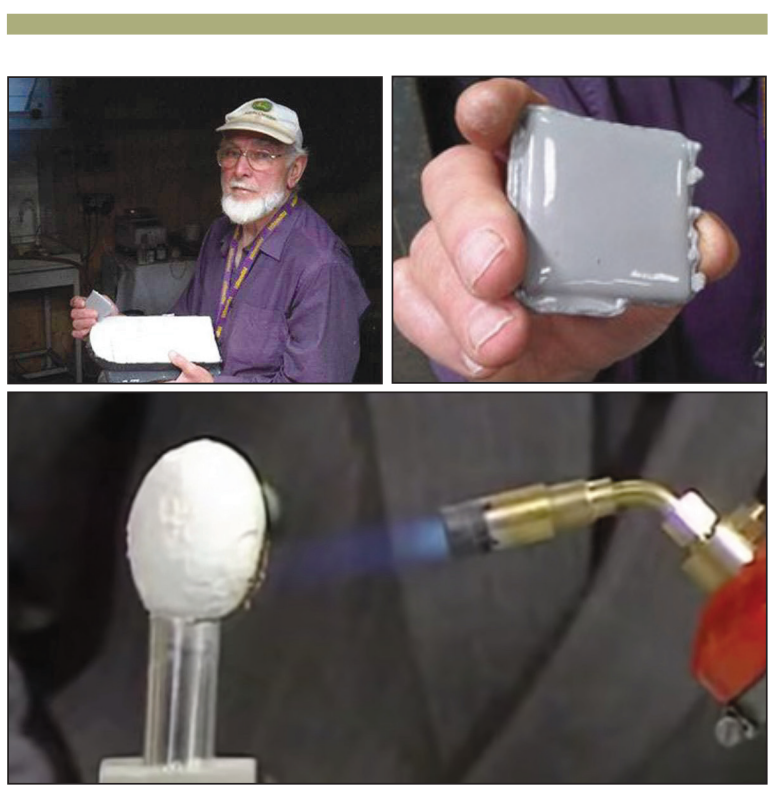

Top: Maurice Ward with his invention, Starlite. Bottom: Still image from 1990 episode of the BBC TV show Tomorrow's World, demonstrating Starlite's heat resistance and strength by wrapping it around an egg and blasting it with a Bunsen burner. Credits: BBC UK. hair products and dyes. People from all over northern England would seek out his coloring artistry. His heads, he boasted, could not be copied.

In the early 1980s, Ward ventured into the plastics business with his purchase of an industrial extruder. Though the machine was intended to stamp out hoods for automobiles, Ward found more value in the scraps it produced. That leftover material, which Ward dubbed "gubbins," would form the base of the bespoke flame retardant he set out to formulate in the wake of the River Orrin tragedy.

At a self-proclaimed rate of 20 new formulations for a flame retardant per day, Ward ultimately happened upon one with which he was satisfied. Able to withstand the $2500^{\circ} \mathrm{C}$ blast from his blowtorch, the pliable substance remained cool to the touch. Thus, Starlite was born.

Everything, it seemed, had culminated in this moment for Ward. The applications of Starlite seemed limitless, reaching well beyond airplane cabin safety. But for years, nothing happened. Whether it was Ward's status as a mere amateur or his viselike grip on the secret to Starlite's true composition, Ward's invention proved as inert to investment as it was to heat. It simply didn't catch onuntil 1990.

Starlite made its official debut on Tomorrow's World, a BBC television program that highlighted advances in science and technology. Pitted against one another in the style of an infomercial demo was an egg coated with Starlite and a bare, ordinary egg. The challenge: which could survive a blowtorch flame longer? The bare egg cracked immediately. Minutes later, host Peter Macann turned to the Starlite-coated egg, switched the torch off, and casually placed the egg in his palmcharred side down. And then the reveal. Macann cracked the still-raw egg into a small glass bowl. "The egg," Macann said, "hasn't even begun to start cooking."

Months later, Ward and his Starlitecoated eggs found themselves at the British Atomic Weapons Establishment at Foulness. It was time to step up the challenge. According to Ward, Starlite was submitted to a battery of tests that included a nuclear flash equivalent to 75 Hiroshimas, which produced temperatures of up to $10,000^{\circ} \mathrm{C}$. The result was the same: runny eggs.

That's when the calls poured in.

Investors hounded Ward for the chance to commercialize his wonder material, with some offering money upfront for a piece of the action. Even NASA was reportedly in the mix. But Ward was unrelenting in his negotiations. At the crux of the matter was Ward's unwillingness to sign any confidentiality agreement, fearing that companies would reverse-engineer Starlite and market their own off-brand versions.

The material was believed to be a type of intumescent paint. Unique for a material that asserted to be thermal- and blastproof, it was claimed to be $90 \%$ organic.

Ward's experiences during that period only tightened his grip on his formula. It would take more than a decade before Ward began warming up to the idea of collaborating more openly. He even started a blog in 2009 to keep readers aware of new developments and invite "suggestions on how to bring Starlite into the commercial market."

Sadly, Maurice Ward passed away in 2011 at the age of 78 .

Despite the openness he shared with followers later in life, Ward kept Starlite's formula a secret. Some reports suggest that Ward divulged the recipe to members of his family. To date, however, no news about Starlite has surfaced: whether it has been fabricated by anyone other than Maurice Ward, whether it exists in some other form today, and perhaps most essentially (and most disappointingly), whether it was all simply too good to be true. 